\title{
Personal determinants of competence of interaction with other people among preschool and primary education teachers
}

\author{
N.V. Savina ${ }^{1 *}$, G.E. Ozhogova ${ }^{2}$, and I.N. Rasskazova ${ }^{3}$ \\ ${ }^{1}$ Omsk state pedagogical University, Omsk, Russia \\ ${ }^{2}$ Omsk state pedagogical University, Omsk, Russia \\ ${ }^{3}$ Omsk state pedagogical University, Omsk, Russia
}

\begin{abstract}
The article substantiates the importance of including several groups of universal competencies, reflecting the integral competence of interaction with other people, into the Federal State Educational Standards of Higher Education (FSES HE) of the Russian Federation. The article presents the results of studying the determinants of personality in this aspect - empathy, proneness to conflict, and tolerance among teachers of primary and preschool education, as well as the positions of their professional and pedagogical activities. The prospects for eliminating the identified deficiencies are shown both at the stage of training a future teacher at a university and in professional activity.
\end{abstract}

\section{A problem statement}

The growing role of key competencies, expertise, and skills of a modern person is due, inter alia, to the need to distinguish their actions from those of artificial intelligence. The fourth industrial revolution, according to Schwab, bears risks of shutting down a number of professions that can be replaced by robots. In this regard, the Report of World Economic Forum "Future of Jobs" 2018 states: "Professions that use unique human-only skills such as empathy, social-emotional intelligence and creativity will become particularly popular" [1]. These skills are above-professional, universal skills that are not limited to any field of activity.

Today, such concepts as "key skills", "metacompetencies", "metaskills", "universal competencies", and "soft skills" do not need any special introduction. The authors define the studied phenomena as universal competencies, although it may be spoken synonymously about key competencies or key skills: "... are there any significant differences when using different terms for "the skills of the 21st century": key competencies, "soft"/"flexible" skills, universal actions, etc. The authors' answer is no. The plurality of terms describes universal abilities that are not limited to a specific task or situation" [2].

${ }^{*}$ Corresponding author: ipcs-profped@yandex.ru 
The modern complication of technologies in all areas of life and work requires collective work, the interaction of individual specialists. Solving complex problems is beyond the power of loners. All this led to the introduction of groups of universal (key) competencies into the FSES HE of the Russian Federation, among which some reflect the competence of interacting with other people in a variety of social contexts: cooperation, collaboration, partnership, etc. In the authors' case, these are groups of universal competencies: "Teamwork and Leadership", "Communication", and "Intercultural Interaction" [3]. Their importance for any professional is also reflected in the report of the World Economic Forum: "Nevertheless, the responsibility for the implementation of the following working tasks still remains mainly with a person: communication and interaction; coordination, development, management and consulting; argumentation and decision making" [1].

Undoubtedly, these groups of competencies are related. Communicative competence is designed to eliminate the conflict of cultures and mentality, the psychological discomfort of intercultural interaction [4, 5]. In turn, intercultural competence is: "the ability to successfully communicate with people of another culture; in the narrow sense of the word, it is the ability to communicate with representatives of other cultures, in the process of which mutual satisfaction is achieved" [6]. Unlike a group, a team is characterized by closer interaction and mutual dependence, team members work exclusively together, which means they communicate a lot. All this requires communication and leadership skills from team members [7].

In modern research, all universal (key) competencies (expertise) are divided into three groups: the competencies of thinking (cognition), interaction with others, and interaction with oneself [8]. In more detail, the competence of interaction with others is revealed through:

- cooperativity, the ability to cooperate, to work together (cooperation/collaboration), including in the role of a leader and in the role of a team member, responsibility and its distribution, coordination of actions within the team; the ability to negotiate (persuade, argue one's position and accept someone else's, as well as take into account social and cultural differences), resolve conflicts, be aware of possible objective contradictions in the interests of different parties and take them into account when making decisions [8];

- the ability to cooperate and interact, establish, develop, and maintain social ties as a leader and a team member, take and distribute responsibility, coordinate team work; the ability to conduct negotiations (the ability to convince others, justify one's position, respect the interests of others, take into account social and cultural diversity), resolve conflicts, understand the possibility of objective conflicts of interest between social groups; the ability to maintain strong and weak ties with people [9].

Based on the above-mentioned, some important personal determinants are highlighted for further study - empathy, tolerance, proneness to conflict as factors affecting the effectiveness of the competence of interaction with others. Their manifestation is considered by the example of teachers - representatives of the profession of the "person-toperson" type, which, in fact, is a constant interpersonal interaction. The authors have already noted earlier the complexity of the teaching profession and the need to maintain the psychosocial health of the teacher. Psychosocial health is defined as an adequate behavioral response of a person (in accordance with the age and educational level), contributing to his or her sufficient activity in society to establish contacts, enter various social groups, and perform different types of activities [10].

Consequently, the competence of interaction with others is the main universal competence for professional pedagogical activity. Through professional pedagogical communication, contacts are established and maintained with students, parents, colleagues, and the administration of the educational organization. In a multinational and multi- 
religious country, such communication will be intercultural, requiring tolerance, ethics, and empathy. Undoubtedly, communication with groups of different social characteristics will be accompanied by conflict situations. Here the teacher must show the skills of conflict resolution, be able to play the role of a mediator. Proneness to conflict, as a personality trait, on the contrary, should ideally not be present.

\subsection{The objective of the work}

Personality traits manifested in interpersonal and social relations, communication, such as tolerance, empathy, and conflictological competence, are important factors in the quality of these relations, communication, and overall well-being of the individual. They are of particular importance for teachers in the development of harmonious relations with different subjects of the educational process. It is no coincidence that communication skills, the ability to communicate in psychology are referred to as the main abilities of a teacher, without which effective pedagogical activity is impossible (Gonobolin, Krutetsky, Markova, Kuzmina, etc.). A teacher's tolerance and conflictological competence are considered by modern scientists as: professionally important qualities of a modern teacher; structural components of his or her personality and communicative competence; necessary conditions for successful professional activity, etc.

Over the past two decades, a significant number of scientific works have been devoted to the problems of studying and forming tolerance among teachers and students of pedagogical educational institutions (Korsun, Sindikova, Chekmareva, Achasova, etc.) and conflictological competence (Maksimova, Tenikhina, Ermolaeva, Pogodina, Yakushin and others). Most of them emphasize the role of the teacher in the formation of children's tolerance. When considering the issues of the teacher's capabilities in the formation of tolerance and conflictological competence in children, the emphasis is placed on two most important aspects: the teacher's attitude towards children, students, his or her personality traits and behavior; the formation of appropriate behavior in children. In order for this activity of a teacher to be effective, it is important to form the structural components of tolerance, which are distinguished by Povarenkov: dynamic (reflect the teacher's system of ideas, his or her values, beliefs, and attitude towards children); operational (knowledge and ability of the teacher, allowing him or her to communicate successfully) [11]. In the concepts of conflictological competence, scientists (Khasan, Fedorenko, etc.) also emphasize the constructive behavior of the teacher himself or herself, his or her ability to establish contact, conduct a dialogue in order to manage the conflict, achieve a positive result [12].

To a large extent, the teacher's behavior depends on the level of proneness to conflict of the personality - a property that reflects the frequency of the entry into conflicts. If a teacher has a high level of conflict, he or she will create conflicts, provoke other people to them, aggravate conflicts between children.

In the authors' study, the attention is paid to the aspect of the formation of these personality traits in a teacher, since only in this case, he or she will be convincing and successful in teaching children tolerant and conflict-free communication. The teacher cannot teach children what he or she does not have. If he or she has a discrepancy between words and actions, deeds, then the children are unlikely to trust him or her. At the same time, as scientists and practitioners note, the problem of conflict behavior of teachers in the modern Russian educational environment is increasing. Understanding the importance of the empathic, tolerant attitude of people towards each other, constructive resolution of emerging conflicts poses the task of forming them in children for society, family, and educational institutions. It is no coincidence that these ideas are reflected in the federal state standards of preschool and primary education, as well as higher pedagogical education. 
These personality traits, like most others, begin to form in childhood, when the child's mental development is intensive, and there is a manifestation of an active interest in the world around him or her, in the assimilation of social norms, rules of behavior, and attitudes towards other people. Unfortunately, as the researchers note, $25 \%$ of Russian children of primary school age have serious problems: insufficient social competence, helplessness in relations with peers, inability to resolve simple conflicts, as well as manifestations of aggression [13].

There are many macro and micro social factors influencing the formation of personality traits associated with focus on another person, with the manifestation of understanding, acceptance, and respect. However, perhaps, one of the most important factors is the characteristics of significant adults from the child's immediate environment, including teachers. Their own example of behavior, attitude towards the child, other people, a conscious desire to help children develop these useful social qualities. The influence of adults on the formation of a child's behavior is conducted at different levels:

- unconscious - children observe adults, identify themselves with them, imitate them. The child's behavior in the process of learning is consolidated, becomes a stable form. Therefore, in the child's assimilation of social norms, the formation of empathy, tolerance, the model of adult behavior that the child observes and which he or she reproduces is of great importance;

- conscious - adults open social norms for the child, take care of their understanding, assimilation, acceptance, and following.

This process occurs in different periods of childhood. In the authors' study, teachers of preschool and primary education are examined, and this is due to the fact that in preschool and primary school age, their role in the life of a child, the formation of the qualities of his or her personality, is of particular importance. An adult, especially a teacher, becomes extremely authoritative and significant for a child. The preschooler goes beyond the family circle, his or her main interest is the world of adults, which he or she plays in his games, whom he or she strives to be like. For younger students, schooling becomes the center of the social situation of development. The teacher is an extremely authoritative person from the adult world for the child. They love him or her, they want to be like him or her, they imitate him or her, pay attention to what he or she says and does.

This importance of teachers, their indisputable authority for children in the period of preschool and primary school age, is a huge resource of the teacher's influence on the formation of the child's personality as a whole, his or her individual qualities, and the system of interpersonal relations. It is no coincidence that representatives of humanistic psychology (Maslow, Rogers) noted that the basis for the formation of a child's mental balance, his or her benevolent, tolerant attitude towards other people was a positive attitude towards him or her - acceptance, understanding, respect, and love [14, 15]. Therefore, theoretical knowledge on the assimilation of social norms, their application by the teacher in practice as methods of fostering tolerance, can be really effective in the system of preschool and primary education. Undoubtedly, this presupposes the highest level of responsibility of the teacher for what is happening with the children. Tolerance as a personality trait, characterized by the ability to accept differences, to build humanistic relationships between people, readiness to understand and cooperate with people, empathy as the ability to comprehend the emotional experiences of another person, and a person's ability to take adequate, constructive actions in difficult, conflict situations have always been important. However, in the modern multicultural space, in connection with the increase in differences in society at all levels (between states, social groups, and individuals), which leads to an increase in disagreements, escalation of violence, they acquire special significance. In addition, children, to a greater extent, in comparison with adults, show intolerance, often in the form of open forms of verbal, physical aggression. 
The behavior of children is less conscious, less predictive, more impulsive, influenced by emotions. In addition, they have insufficiently formed moral ideas, volitional qualities, selfregulation, and self-awareness.

Therefore, it is not in vain that the problems of tolerance, empathy, and conflicts have received the active attention of scientists and practitioners in recent years, including the issues related to their formation in the educational environment and the role of teachers in this work. The works of many foreign scientists, such as Scott [16], Withers [17], Regnet [18], and domestic scientists, such as Antsupov [19], Verbitsky [20], Chekmareva [21] are devoted to conflicts and the ways to overcome them, the formation of constructive strategies for resolving conflicts.

In understanding tolerance, scientists place an emphasis on different features of interpersonal relationships. However, what they have in common is the humanistic orientation of the personality in relation to other people, groups, manifested at different levels: emotional - acceptance; cognitive - understanding; behavioral - providing support, care. It is the manifestation of such an attitude towards children and other subjects of the educational process that testifies to the high level of development of tolerance among teachers.

Unfortunately, teachers are not always tolerant. Sometimes, they are a model of intolerance to the whole group as a whole, or to individual children, demonstrating a preference for some and persistent neglect in relation to others. As a result of such an unequal, unfair attitude, a barrier arises between the child and the teacher, and the degree of authority and the possibility of his or her influence are reduced. Conversely, children value and respect teachers who show a fair, equal attitude towards them. A teacher trying to understand the feelings and meaning of a child's behavior will almost always (with the possible exception of serious pathology in development) be able to find a response from him or her. At the same educational institution, children can relate to teachers in very different ways: respect and love some of them; hate and fear others. This is largely determined by the personality and behavior characteristics of the teachers themselves.

In the article, the personality traits of teachers are investigated, which, from the authors' point of view, have a relationship. The higher the level of the ability to understand and accept another person is, the less conflictive the person will behave, the more he or she will strive to resolve the contradictions that arise on the basis of respect for another person, taking into account his or her rights and interests. On the contrary, with an unformed orientation towards other people, a positive attitude towards them, a person takes care only of himself or herself, his or her interests, strives to win at any cost. The higher the level of a person's ability to understand a person's experiences (empathy), the more he or she will be able to accept it (tolerance). Accepting a person, he or she is more able to understand his or her feelings.

Therefore, taking into account the special influence of preschool and primary education teachers on the development of children and certain qualities of their personality, which were revealed above, in the empirical part of the authors' study, the degree of expression of these properties in the teachers themselves was examined.

\section{Materials and the results of the research}

The highlighted theoretical and methodological foundations allowed formulating empirical research tasks: to identify the level of formation of teachers (using the example of preschool and primary education teachers) of personal determinants of interaction with other people - empathy, tolerance, proneness to conflict in the subjects; and also to determine the positions (models) of the teacher's professional pedagogical activity; make a comparative analysis of the correspondence of these personal determinants with the model 
of activity. Acting as a stable psychological formation, the professional communicative position in its entirety reflects the communicative style characteristics of the teacher's activity. Based on the obtained results, the problem of determining ways to eliminate deficiencies in the personality and activities of teachers will be solved.

In order to study the formation of personal and professional prerequisites for the development of general professional communicative competencies that a teacher should have, the authors conducted an empirical study. The study involved 60 teachers of primary and preschool education in Omsk and the Omsk Region. For the research, the following methods and techniques were used: the method of conversation; the questionnaire "Diagnostics of the presence of empathy, tolerance, and proneness to conflict of a teacher" (this questionnaire is based on the questions of the author's methods by Boyko and Yusupov) $[22,23]$; the method of diagnostics of the communicative professional position of the teacher (Sitarov and Maralov) [24].

As it was noted above (in the course of the theoretical analysis of this article), the formation and development of universal communicative competencies are impossible without determining the level of development of the communicative qualities of the teacher's personality. They have a significant impact on the productivity of professional and pedagogical activities and the emotional comfort of the educational process. The atmosphere of professional communication permeates all the teacher's activities. Moreover, communicative competence is an integral characteristic, which reflects the personal and professional characteristics of a teacher. It can include the formed communication skills, as well as the abilities, skills, and communication qualities of the teacher's personality. The results of studying proneness to conflict, tolerance, and empathy are presented in Table 1.

Table 1. Levels of manifestation of proneness to conflict, tolerance, and empathy among teachers, in percent.

\begin{tabular}{|l|l|l|l|}
\hline \multirow{2}{*}{$\begin{array}{l}\text { Manifestation } \\
\text { levels }\end{array}$} & Personal qualities & \multicolumn{2}{|l|}{} \\
\cline { 2 - 4 } & Proneness to conflict & Tolerance & Empathy \\
\hline low & $43.3 \%(\mathrm{n}=26)$ & $20 \%(\mathrm{n}=12)$ & $10 \%(\mathrm{n}=6)$ \\
\hline average & $36.7 \%(\mathrm{n}=22)$ & $46.7 \%(\mathrm{n}=28)$ & $36.7 \%(\mathrm{n}=22)$ \\
\hline high & $20 \%(\mathrm{n}=12)$ & $33.3 \%(\mathrm{n}=20)$ & $53.3 \%(\mathrm{n}=32)$ \\
\hline
\end{tabular}

The obtained data indicate the predominance of the average and high level of development of tolerance and empathy. This indicates that the teachers participating in the study are moderately tolerant of differences in views and beliefs and negatively regard religious, national, confessional, and other prejudices.

If one turns to the essence of the concept of "tolerance", then in relation to the personality of a teacher, the acceptance of a child regardless of the various factors accompanying his or her personality is an important condition for establishing pedagogical contact and cooperation with him or her.

Revealing the features of the manifestation of empathy (a high level in 53.3\% and an average level $-36.7 \%$ ) in the subjects, it can be noted that teachers show emotional involvement, try to understand the peculiarities of the child's inner world and his or her experiences. They are able to show compassion and empathy in those situations when it is required.

On the contrary, as the tabular data show, the subjects have a low level of proneness to conflict $(43.3 \%)$. The average one was found in $36.7 \%$. These quantitative results indicate that teachers in social contacts rarely provoke conflicts, are not inclined to conflictive behavior and the manifestation of aggression in interpersonal contacts. It can be noted that teachers are focused on dialogue and compromise in communication, show restraint and tolerance. In general, the analysis of the manifestation of such personal qualities as 
tolerance, empathy, and proneness to conflict indicate the positive development of these professionally important personality traits.

Furthermore, a correlation analysis was conducted (according to r-Pearson) of these personal qualities. The clearly identified correlations are presented in the form of a constellation in Fig. 1.

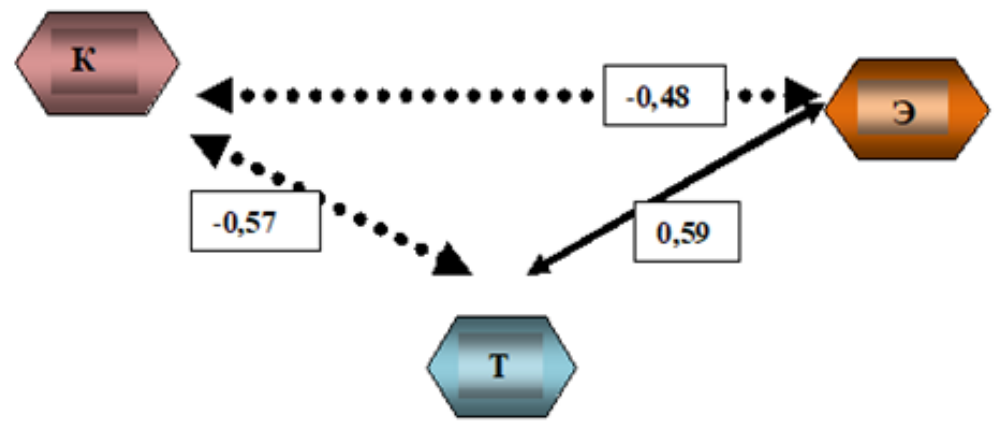

Note:

$\mathbf{K}$ - the proneness to conflict of a teacher;

$\mathbf{E}$ - empathy of a teacher;

$\mathbf{T}$ - tolerance of a teacher;

moderate negative relationship when $\mathrm{p}=0.001\left(\mathrm{r}_{\text {crii }}=0.421\right)$ for $\mathrm{n}=60$ moderate positive relationship when $\mathrm{p}=0.001\left(\mathrm{r}_{\text {cri }}=0.421\right)$ for $\mathrm{n}=60$

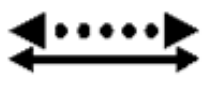

Fig. 1. The relationship of professional and personal qualities of teachers.

As can be seen from the visual presentation of the data of the correlation constellation, in the first place in terms of the strength of the connection there is a direct moderate positive relationship between tolerance and empathy $(\mathrm{r}=0.59)$. The obtained coefficient shows that the degree of development of tolerance is associated with the development of empathy: the higher the tolerance of a person is, the more developed is empathy. This relationship is psychologically explainable: tolerant individuals respect the views, opinions, and interests of other people, show flexibility in interpersonal interaction, tolerate everything (beliefs, religion, attitudes, etc.) that contradicts or does not correspond to their point of view. The existing discrepancies do not interfere with their communication and interaction. Most likely, tolerant individuals have a higher level of emotional involvement, they "deeper" understand the emotional state of another person, are ready to show sympathy and emotional support.

Moreover, a moderate inverse correlation relationship between conflict and tolerance $(\mathrm{r}=-0.57)$ can be noted. The inverse relationship between these indicators indicates that the higher the teacher's tolerance is, the less proneness to conflict is expressed. His or her respect for the personality of the child, acceptance of features helps to reduce the degree of conflict. A moderate inverse relationship between conflict and empathy $(\mathrm{r}=-0.48)$ is noted. Emotional involvement, sensitivity, and the ability to empathize contribute to a decrease in proneness to conflict of a personality.

The next stage of the authors' empirical research was to identify the position (model) of the teacher's professional pedagogical activity. The obtained results are clearly shown in Fig. 2. 


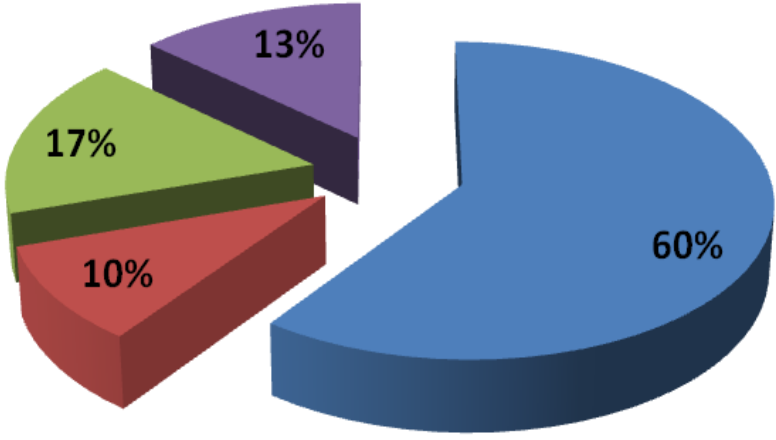

Expressed personal model of professional-pedagogical activity $(\mathrm{n}=8)$

Fig. 2. Positions (models) of the teacher's professional and pedagogical activity.

In the authors' study, the educational and disciplinary model prevails (60\%). The rest of the models are expressed insignificantly (from 10 to 17\%). Such a ratio of quantitative data indicates that teachers generally gravitate towards an authoritarian, directive style of communication with the subjects of the educational process and leadership of the children's team. The main tactics of interaction are guardianship and dictate. All activities are strictly regulated by the teacher. In professional communication, the teacher practices: instructions, explanations, prohibitions, and requirements, sometimes threats, notations, shouting, and punishment are possible. The teacher, in this position, connects the effectiveness of professional activity with the transfer of knowledge, the educational process is strictly regulated by him or her. It is in this that he or she sees the success of his or her work. From the point of view of psychological comfort, children experience stiffness, often experience tension, anxiety, and fear if the teacher's requirements are not met. In relation to the teacher, alienation may arise, because all the child's mental resources are directed towards self-defense.

An alternative to the educational and disciplinary model is the personality-oriented one $(13.3 \%)$. It is possible to characterize teachers with a predominance of this model as flexible, inclined to cooperate and to show equality. They know how to stand up to the point of view of a child, are inclined to show empathy, are sensitive and tolerant. The leadership of the children's team adheres to a democratic style. In pedagogical work, such teachers are aimed not only at transferring knowledge, abilities, and skills to children but also at the development of personality, creative individuality, trying to develop the child's abilities to the maximum. In teaching and educational work with children, they adhere to a differentiated approach, taking into account the individual characteristics of children. Unfortunately, the percentage of teachers in the sample with a predominance of this type is low.

If these methods are compared, then attention can be drawn to the objective contradiction. With a sufficient expression of the communicative qualities of the individual (tolerance, empathy, and moderately expressed proneness to conflict), the directive model of professional communication prevails in the subjects $(60 \%)$. This contradiction can be explained by the fact that, first, the identified level of the communicative qualities of a person can be declarative. Most likely, the subjects themselves are not fully aware of the 
differences between the required communicative qualities of the individual and those actually existing. Second, the communicative component of the individual style of activity is not sufficiently formed. The subjects are well aware of the professionally important communicative qualities of the individual and the requirements of the profession, but the implementation of these qualities, due to objective circumstances or other subjective factors, is significantly difficult.

\section{Conclusions}

The importance of universal competencies in the training of any specialist is constantly growing in a changing world. One of these competencies is communicative competence, which is also the competence of interacting with others. It is especially important for teachers as representatives of the profession, where the basis is interaction with different groups of people. Its effective implementation in the teacher's professional activity is influenced by such personal determinants as empathy, tolerance, and proneness to conflict. By the example of studying the manifestation of these phenomena in preschool and primary education teachers, it can be stated that there is a fairly high level of development of empathy and tolerance and a low level of proneness to conflict, which is a positive result. The authors also identified the following relationship between the studied personality traits: the higher the teacher's personality tolerance is, the more empathy is developed and the less pronounced is the proneness to conflict. This is a rather good trend. At the same time, the problem is the predominance of the directive model of professional communication among teachers, which is extremely undesirable, since it can negatively "reflect" on the condition of children, their attitude towards the teacher, etc. The obtained results indicate some inconsistency in the personal and activity spheres. Probably, the reason for using not the most effective - directive model of professional communication by the majority of teachers, especially in the system of preschool and primary education, when children are the most defenseless, vulnerable, and dependent, is not the knowledge component, but other factors. For example, the convenience of using this model in relations with children: children are afraid of the teacher and obey the requirements, therefore, the external result of educational activity will be achieved.

All of the above-mentioned allows proposing a number of recommendations and outlining ways for further research. First, at the state level, to revise the ways of organizing and monitoring the professional training of a teacher. Namely, the competencies defined in the standard must be reflected in adequate content, then the theoretical knowledge gained during the training of a specialist will not disagree with professional attitudes and skills. Second, at the regional level, through a system of organized practical and laboratory classes, to strengthen the practical training of a specialist, which will make it possible to timely identify flaws, deficiencies, and contradictions and outline ways of professional development and improvement of a young teacher. From these positions, in the authors' opinion, additional material and moral stimulation of a young specialist and the development of the institution of mentoring is required. Third, at the individual level of a particular specialist, constant work on oneself, self-development of the necessary professionally important communicative qualities of the individual, and an understanding of the absence of an end point in this process are required. Namely, such a professional attitude serves as the basis for the development of professional competence, personal development in the profession, and true pedagogical mastery. Additional studies of such factors of the competence of interaction with other people among teachers as the level of formation of professional reflection, the state of psychosocial health, psychoemotional burnout seem promising. Moreover, the research should be differentiated according to the profile of the teacher's activity, length of service, age, and other characteristics. 


\section{References}

1. The information resource «World Economic Forum. The 10 skills you need to thrive in the Fourth Industrial Revolution, available at», Switzerland, access mode: https://www.weforum.org/agenda/2016/01/the-10-skills-you-need-to-thrive-in-thefourth-industrial-revolution/

2. M.S. Dobryakova, I.D. Frumin, Universal competences and new literacy: from slogans to reality, p. 474 (Ed. by M.S. Dobryakova, I.D. Frumin, Moscow.: High School of Economics, 2019)

3. The information resource "Federal state educational standard (3++) for bachelor's and master's degrees. Portal of Federal state higher education standards», Russia, access mode: http://gosvo.ru/fgosvo/152/150/25/115

4. A.A. Isakova, Integration of Education, 21, 1, 46-53, (2017)

5. S.G. Ter-Minsarova, Contradictions of international communication in the era of globalisation obstacles or driving forces?, Bulletin of the Peoples' Friendship University of Russia. Ser.: Linguistics, 19 (4), 43-48 (2015)

6. I.L. Bim, Foreign language in the system of school philological education (concept). Foreign languages at school, 1, 4-9, (2009)

7. Yu.N. Lapygin, Project team or project team. Scholarly notes. 1, 42-47, (Publisher: Vladimir Branch of the Federal State Budgetary Educational Institution of Higher Education "Russian Academy of National Economy and Public Administration under the President of the Russian Federation, 2019)

8. I.D. Frumin, M.S. Dobryakova, K.A. Barannikov, I.M. Remorenko, Universal Competencies and New Literacy: What to Teach Today for Tomorrow's Success. Preliminary conclusions of the international report on trends in the transformation of school education. Modern analytics of education, 2 (19), 28, (2018)

9. M. Granovetter, The strength of weak ties, The American Journal of Sociology, 78 (6), 1360-1380 (1973)

10. N.V. Savina, Competitiveness of Pedagogical University Graduates as a Factor of Psychosocial Health, Problems of modern teacher education, 57-12, 257-266 (2017)

11. Yu.P. Povarenkov, Psychological characteristics of the teacher's professional tolerance, Questions of the psychology of attention: collection of articles, 21, 256 (Scientific. works, Saratov: publishing house Sarat. University, Issue. 2013)

12. B.I. Khsan, E.Iu. Fedorenko, Conflicts, Negotiations and Risks in Educational Relationships, Journal of Siberian Federal University. Humanities \& Social Sciences, 7 (4), 619-627 (2014)

13. D.I. Feldstein, Profound changes in modern childhood and the resulting actualization of psychological and pedagogical problems of education development, access mode:://refdb.ru/look/2311497.html

A. Maslow, The Psychology of Being, p. 304 (Moscow: Refl-book, Kiev: Vakler, 1997)

14. K. Rogers, Formation of personality. A look at psychotherapy, p. 416 (Moscow: Eksmo-Press, 2001)

15. D.G. Scott, Conflicts and ways to overcome them, p. 190 (Kiev: Vneshizdat, 1991)

16. B. Withers, Conflict management, p. 174 (SPb.: Publishing house Peter, 2004)

17. E. Regnett, Conflicts in organizations. Forms, functions and ways of overcoming, p. 396 (Kh.: Publishing house of the Institute of Applied Psychology "Humanitarian Center", 2005) 
18. A.Ya. Antsupov, Prevention of conflicts in the school team (Moscow: Humanities. ed. center VLADOS, 2004).

19. A.A. Verbitsky, O.I. Shcherbakova, Conflictological culture of a specialist: technologies of formation, p. 413 (Moscow: Moscow State Pedagogical University, 2016).

20. T.N. Chekmareva, Problems and contradictions in the development of tolerance in the higher education system as a professionally important quality of a future teacher, Problems of socio-economic development of Siberia, 1 (7), 107-119, (2012).

21. R.A. Limonchenko, N.S. Lemyasova, Empathy and problems of professional suitability of diagnostic procedures (on the example of the analysis of I. M. Yusupov's method), Scientific e-journal " PEM: Psychology. Educology. Medicine " issn 23129352 (Online), 2, 166-186, 2016

22. V.V. Boyko, Energy of emotions: Emotions in communication, emotions in the manifestations of personality, the creative power of emotions, methods for studying emotions (SPb: Peter, 2004)

23. S.V. Pazukhina, Assessment of the environmental level of pedagogical consciousness of future teachers, Ecology of education and science, 8, 6-32, (2016) 